\title{
BCR/ABL1 Fusion Gene p190
}

National Cancer Institute

\section{Source}

National Cancer Institute. BCR/ABL1 Fusion Gene p190. NCI Thesaurus. Code C99305.

A fusion gene that results from a chromosomal translocation $t(9 ; 22)(q 34 ; q 11)$ that fuses exon 1 of the $B C R$ gene to the 5 ' side of exon 2 of the ABL1 gene. This rearrangement is associated with acute lymphoblastic leukemia. 